\title{
Low-Temperature Synthesis of Vanadium Dioxide Thin Films by Sol-Gel Dip Coating Method
}

\author{
Ladawan Chotirat $\mathbb{D},{ }^{1,2,3}$ Sutham Niyomwas, ${ }^{1,2,4}$ Witthawat Wongpisan, ${ }^{5}$ \\ and Sitthisuntorn Supothina $\mathbb{D}^{5}$ \\ ${ }^{1}$ CENE Center of Excellence in Nanotechnology for Energy, Prince of Songkla University, Hat Yai 90112, Thailand \\ ${ }^{2}$ CEMME Center of Excellence in Metal and Materials Engineering, Prince of Songkla University, Hat Yai 90112, Thailand \\ ${ }^{3}$ Department of Mining and Materials Engineering, Faculty of Engineering, Prince of Songkla University, Hat Yai 90112, Thailand \\ ${ }^{4}$ Department of Mechanical Engineering, Faculty of Engineering, Prince of Songkla University, Hat Yai 90112, Thailand \\ ${ }^{5}$ National Metal and Materials Technology Center, Thailand Science Park, Pathum Thani 12120, Thailand \\ Correspondence should be addressed to Sitthisuntorn Supothina; sitthis@mtec.or.th
}

Received 5 April 2021; Accepted 4 June 2021; Published 17 June 2021

Academic Editor: Hongmei Luo

Copyright ( 92021 Ladawan Chotirat et al. This is an open access article distributed under the Creative Commons Attribution License, which permits unrestricted use, distribution, and reproduction in any medium, provided the original work is properly cited.

\begin{abstract}
The vanadium dioxide $\left(\mathrm{VO}_{2}\right)$ thin films were synthesized by sol-gel dipping on a glass slide substrate at low temperature of $500^{\circ} \mathrm{C}$ in a vacuum tube furnace at a pressure of $2 \times 10^{-3} \mathrm{mbar}$ by 2 -step calcination without an intermediate gas purging. Synthesis conditions, including temperature, vacuum pressure, and calcination steps in the vacuum tube furnace, were investigated to find the optimum condition that promoted the formation of $\mathrm{VO}_{2}$ phase. It was found that the $2^{\text {nd }}$ calcination step was very important in realizing the monoclinic vanadium dioxide $\left(\mathrm{VO}_{2}(\mathrm{M})\right)$. The results of the valence electron analysis revealed the outstanding phase of $\mathrm{VO}_{2}$ and a small amount of $\mathrm{V}_{2} \mathrm{O}_{5}$ and $\mathrm{V}_{2} \mathrm{O}_{3}$ phases. The small crystallites of the $\mathrm{VO}_{2}$ were homogeneously distributed on the surface, and the grain was of an irregular shape of $\sim 220-380 \mathrm{~nm}$ in size. The film's thickness was in a range of $69-74 \mathrm{~nm}$. The film exhibited a metal-to-insulator transformation temperature of $\sim 68^{\circ} \mathrm{C}$ and good thermochromic property. Visible optical transmittance remained at $\sim 40-50 \%$ when the sample's temperature changed from 25 to $80^{\circ} \mathrm{C}$ for a near infrared (NIR) region.
\end{abstract}

\section{Introduction}

Vanadium oxide presents a partly-filled $3 \mathrm{~d}$ orbital, leading to the formation of several oxides such as $\mathrm{VO}, \mathrm{V}_{2} \mathrm{O}_{3}, \mathrm{~V}_{4} \mathrm{O}_{7}$, $\mathrm{VO}_{2}, \mathrm{~V}_{2} \mathrm{O}_{5}$, and $\mathrm{V}_{6} \mathrm{O}_{13}$, which all belong to the series of Magneli $\left(\mathrm{V}_{\mathrm{n}} \mathrm{O}_{2 \mathrm{n}-1}\right)$ and Wadsley $\left(\mathrm{V}_{2 \mathrm{n}} \mathrm{O}_{5 \mathrm{n}-2}\right)$ systems [1-3]. Among these oxides, monoclinic vanadium dioxide $\left(\mathrm{VO}_{2}\right.$ (M)) has gained most attention owing to its fascinating thermochromic property that can switch a phase structure reversibly between a monoclinic (semiconductor) and a rutile (metal) phase at about $68^{\circ} \mathrm{C}[3,4]$ in response to external stimuli, leading to dramatic changes in the electrical and optical properties. The change of optical property from infrared-transmitting at low temperature to infraredreflecting at temperatures higher than the monoclinic-rutile phase transition temperature, while maintaining the visible transmittance, makes the vanadium dioxide a promising candidate as thermochromic coating for a variety of devices such as smart windows, tunable absorbers and emitters, and thermal rectification $[4,5]$.

The thermochromic $\mathrm{VO}_{2}(\mathrm{M})$ thin films have been prepared by several methods. The most typical methods include physical vapor deposition, chemical vapor deposition, and sol-gel method. The physical and chemical vapor depositions can precisely control the stoichiometry of films by monitoring oxygen partial pressure. However, the complex deposition processes and expensive equipment significantly limit their practical applications $[6,7]$. The solgel method has been widely employed for material investigation because of several advantages. For instance, it can be coated on complex shape, large substrate. The process is of low cost, and there is easy control of reaction kinetics and 
atomic doping. In addition, lower calcination temperature is typically required to obtain crystalline structure [8-10]. In a typical sol-gel process for $\mathrm{VO}_{2}$ preparation, a $\mathrm{V}^{5+}$-containing precursor is firstly prepared, and then the precursor is deposited onto a clean, hydrophilic substrate through dip or spin coating. The obtained sample is dried and calcined typically at $\geq 600^{\circ} \mathrm{C}[11-13]$ to transform an amorphous phase to a desired crystalline structure. Meanwhile, part of $\mathrm{V}^{5+}$ ions was reduced to $\mathrm{V}^{4+}$ ions $[8,11]$.

For commercial applications, such as smart window coating, glass is the desirable substrate. The soda lime glass is the most common and cheapest one $[14,15]$. Considering that, for wet-chemical processes, the crystalline $\mathrm{VO}_{2}$ phase is typically formed by a high-temperature treatment process. This would restrict the calcination of $\mathrm{VO}_{2}$ thin films on the soda lime glass substrate which is generally tempered at approximately $600^{\circ} \mathrm{C}$. The glass begins to soften at this temperature. The strength of the tempered glass would be weakened after $\mathrm{VO}_{2}$ thin film deposition at temperatures higher than its softening temperature. Therefore, for soda lime glass panel substrates, low-temperature deposition $\left(<600^{\circ} \mathrm{C}\right)$ is of significant importance for the $\mathrm{VO}_{2}$ thin film preparation under inert atmosphere, e.g., vacuum or $\mathrm{N}_{2} / \mathrm{Ar} /$ $\mathrm{H}_{2} / \mathrm{CO} / \mathrm{CO}_{2}[7,8,10,12,14,16,17]$. Moreover, most of the methods reported in literatures employed low vacuum pressure of tube furnace, which utilizes high power of the turbo and diffusion vacuum pumps $[10,12,14,17]$. In some cases, intermediate gases were purged in the tube furnace, during calcination, to prevent film's surface from oxidation in the atmosphere $[7,8,12,14,16,17]$.

In this work, the outstanding $\mathrm{VO}_{2}(\mathrm{M})$ phase was prepared via sol-gel dip coating on a soda lime glass slide at low calcination temperature of $500^{\circ} \mathrm{C}$ by using only a turbo pump to generate low vacuum pressure of $2 \times 10^{-3} \mathrm{mbar}$ in a tube furnace. Moreover, no intermediate gas was purged during a reducing step. Synthesis conditions, which include vacuum pressure, calcination temperature, and steps in the vacuum tube furnace, were investigated. Electrical resistance and optical properties of the prepared vanadium dioxide film were characterized.

\section{Materials and Methods}

2.1. Synthesis of Vanadium Oxide Thin Films. The vanadium oxide thin films were prepared by the sol-gel process, in which a precursor solution was prepared according to the literatures $[17,18]$. In a typical synthesis method, $0.3 \mathrm{~g} \mathrm{~V}_{2} \mathrm{O}_{5}$ powder (99.5\%, Sigma-Aldrich Co., Ltd.) was dissolved in $30 \mathrm{~mL} \mathrm{30 \%} \mathrm{H}_{2} \mathrm{O}_{2}$ (35\%, Chem-Supply Co., Ltd.) with rigorous stirring for $30 \mathrm{~min}$. At this step, the reaction was strongly exothermic, and the solution's color changed from yellow to dark red sol upon a continuous stirring. After the two chemicals were mixed and aged for 2 days at room temperature, thin films were obtained by dip coating method using a dip coater (Model DC-150) performed at a dipping time of $2 \mathrm{~min}$ and a withdrawal rate of $6 \mathrm{~mm} / \mathrm{min}$ on a glass slide substrate. The substrates were cleaned by means of ultrasonication for $30 \mathrm{~min}$ in deionized water, $20 \%$ acetone, $70 \%$ iso-propanol, and $20 \%$ ethanol, respectively. The as- deposited thin films were dried in ambient air for $24 \mathrm{~h}$. The dried thin films were calcined at room temperature, 400, 450, and $500^{\circ} \mathrm{C}$, in vacuum tube furnace at pressures of $2 \times 10^{-2}$ and $2 \times 10^{-3}$ mbar. To investigate an effect of heat treatment, calcination was conducted by 1 - and 2-step calcination, in which each step employed a heating rate of $2^{\circ} \mathrm{C} / \mathrm{min}$ and soaking time of $3 \mathrm{~h}$. For the 1-step calcination, the thin films were heated in a tube furnace to 400,450 , and $500^{\circ} \mathrm{C}$, soaked at this temperature for $3 \mathrm{~h}$, and cooled down to room temperature. The 2-step calcination was carried out in a tube furnace at $500^{\circ} \mathrm{C}$ using the same heating and cooling cycles, noted that the glass slide substrate employed in this work began to soften at a temperature of $\sim 500^{\circ} \mathrm{C}$; thus, calcination temperature did not exceed $500^{\circ} \mathrm{C}$. Process parameters for film deposition are provided in Table 1.

2.2. Thin Film Characterization. Crystal structure characterization of the thin films was performed by using an X-ray diffractometer (XRD; Rigaku TTRAX III). Morphology and thickness were studied by using a scanning electron microscope (SEM; Quanta $400 \mathrm{FEI}$ ) performed in a top and tilted view, respectively. Films' compositions, as well as an elemental mapping, were analyzed by using an energy dispersive X-ray spectrometer (EDS). Oxidation states of the elements were analyzed by using an X-ray photoelectron spectrophotometer (XPS; AXIS Ultra DLD). The binding energy was calibrated with carbon $(\mathrm{C} 1 \mathrm{~s}=284.8 \mathrm{eV})$.

Electrical property of the thin film was determined by an AC four-point probe method. The measurement was conducted in a closed chamber with controlled temperature. During heating and cooling cycles, the film temperature was raised from room temperature to $100^{\circ} \mathrm{C}$ and subsequently reduced to room temperature step by step. The metal-toinsulator (MIT) phase transition temperature is defined as the average of the transition temperature $\left(T_{\mathrm{c}}\right)$ in the electrical property. The $T_{\mathrm{c}}$ is defined as follows [19]:

$$
T_{c}=\frac{\left[T_{c}(\text { heating })+T_{c}(\text { cooling })\right]}{2} .
$$

Transparency of the film coated on the soda lime glass was determined at 25 and $80^{\circ} \mathrm{C}$ by using a UV-Vis-NIR spectrophotometer (Shimadzu UV-3600 Plus) in a wavelength range $200-2500 \mathrm{~nm}$. The bare soda lime glass was employed as a blank sample. Temperatures were controlled at 25 and $80^{\circ} \mathrm{C}$ with applied current electricity.

\section{Results and Discussion}

3.1. Synthesis of Vanadium Oxide Thin Films by Sol-Gel Dip Coating. It has been realized that it is difficult to fabricate pure monoclinic phase $\mathrm{VO}_{2}$ thin film due to its instability under a general synthesis process. It is most likely that more stable vanadium oxides, such as $\mathrm{V}_{2} \mathrm{O}_{5}, \mathrm{~V}_{2} \mathrm{O}_{3}$, and $\mathrm{V}_{6} \mathrm{O}_{13}$, are also present. These oxides block the reversible phase transition from metallic state to insulating state of the monoclinic $\mathrm{VO}_{2}$. Among all of the $\mathrm{V}-\mathrm{O}$ system, the $\mathrm{V}_{2} \mathrm{O}_{5}$ is a highly stable phase $[20,21]$. Thus, in order to investigate the optimum synthesis condition, the presence of crystalline phases was initially considered. Figure 1 shows XRD 
TABLE 1: Fabrication parameters of $\mathrm{VO}_{2}, \mathrm{~V}_{2} \mathrm{O}_{5}$, and $\mathrm{V}_{6} \mathrm{O}_{13}$ thin films.

\begin{tabular}{lccc}
\hline Phase & Furnace temperature $\left({ }^{\circ} \mathrm{C}\right)$ & Vacuum pressure (mbar) & Calcination (step) \\
\hline Amorphous & Room temperature & $2 \times 10^{-2}$ & 1 \\
$\mathrm{~V}_{2} \mathrm{O}_{5}$ & 400 & $2 \times 10^{-2}$ & 1 \\
$\mathrm{~V}_{2} \mathrm{O}_{5}$ & 450 & $2 \times 10^{-2}$ & 1 \\
$\mathrm{VO}_{2}+\mathrm{V}_{2} \mathrm{O}_{5}$ & 500 & $2 \times 10^{-2}$ & 1 \\
$\mathrm{VO}_{2}+\mathrm{V}_{2} \mathrm{O}_{5}+\mathrm{V}_{6} \mathrm{O}_{13}$ & 500 & $2 \times 10^{-3}$ & 1 \\
$\mathrm{VO}_{2}$ & 500 & $2 \times 10^{-3}$ & 2 \\
\hline
\end{tabular}

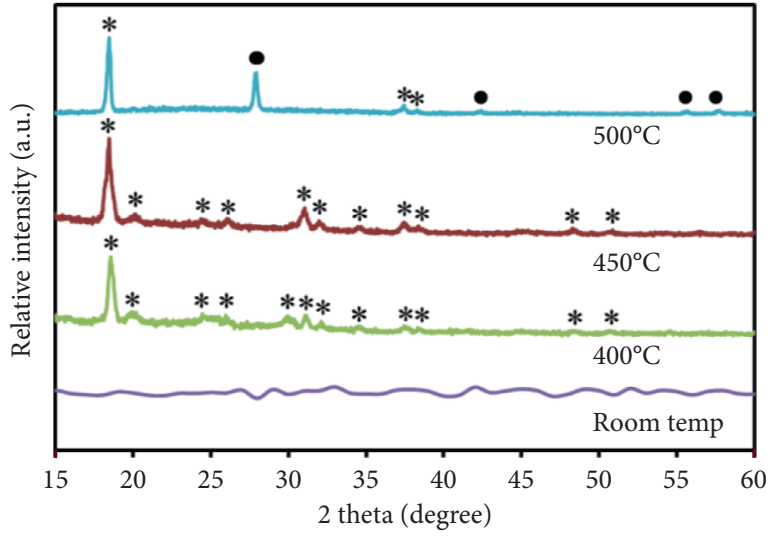

- $\mathrm{VO}_{2}$ * $\mathrm{V}_{2} \mathrm{O}_{5}$

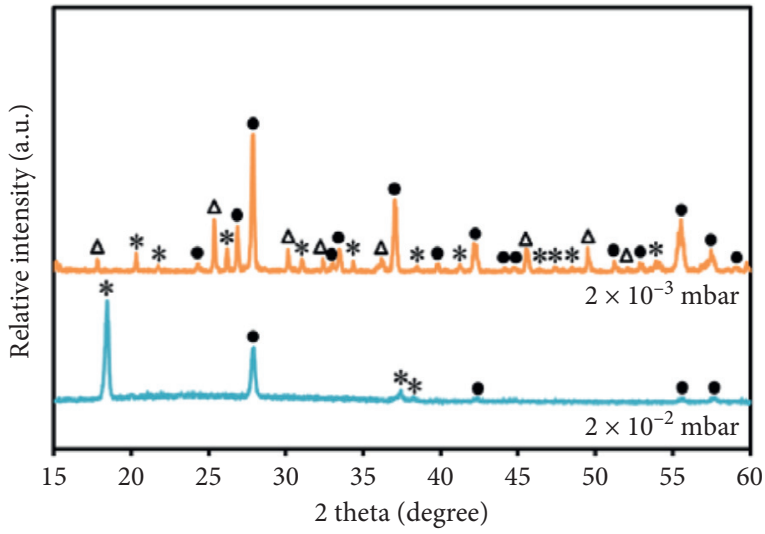

- $\mathrm{VO}_{2}$

* $\mathrm{V}_{2} \mathrm{O}_{5}$

$\Delta \mathrm{V}_{6} \mathrm{O}_{13}$

(a)

(b)

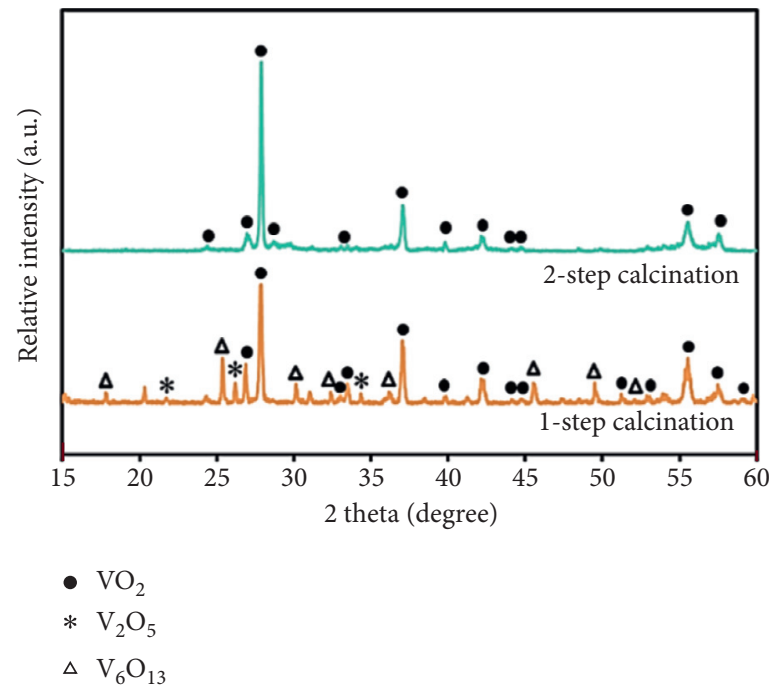

(c)

FiguRE 1: XRD patterns of the vanadium oxide thin films prepared at various conditions: (a) $\mathrm{T}=\mathrm{RT}, 400,450$, and $500^{\circ} \mathrm{C}\left(P=2 \times 10^{-2} \mathrm{mbar}, 1\right.$-step calcination), (b) $P=2 \times 10^{-2}$ and $2 \times 10^{-3} \mathrm{mbar}\left(T=500^{\circ} \mathrm{C}\right.$, 1-step calcination), and (c) 1 - and 2-step calcination $\left(P=2 \times 10^{-3} \mathrm{mbar}, T=500^{\circ} \mathrm{C}\right)$.

patterns of the vanadium oxide thin films after calcined at various conditions summarized in Table 1.

For the 1-step calcination (Figure 1(a)), the temperatures were controlled at 400,450 , and $500^{\circ} \mathrm{C}$, respectively, and the pressure was fixed at $2 \times 10^{-2}$ mbar. XRD analysis of the dried thin film (denoted as "room temperature") revealed amorphous nature signified by the absence of diffraction peak. XRD patterns of the thin films calcined at 400 and $450^{\circ} \mathrm{C}$ show diffraction peaks at $18.7^{\circ}, 20.1^{\circ}, 24.7^{\circ}, 26.2^{\circ}$, $30.1^{\mathrm{o}}, 31.3^{\mathrm{o}}, 32.4^{\mathrm{o}}, 34.8^{\mathrm{o}}, 37.6^{\mathrm{o}}, 38.6^{\mathrm{o}}, 48.6^{\mathrm{o}}$, and $51.1^{\mathrm{o}}$, which correspond to the (001), (101), (201), (110), (301), (400), (111), (211), (401), (311), (302), and (012) planes, 
respectively, of the orthorhombic $\mathrm{V}_{2} \mathrm{O}_{5}$ (ICCD card no. 04015-2250). Increasing the calcination temperature results in an increased intensity of the XRD peaks, indicating an increase of film's crystallinity. For the thin film calcined at $500^{\circ} \mathrm{C}$, its XRD pattern reveals the peaks at $27.7^{\circ}, 42.5^{\circ}$, $55.7^{\mathrm{o}}$, and $57.8^{\circ}$ corresponding to the (011), (210), (220), and (211) planes, respectively, of the monoclinic $\mathrm{VO}_{2}$ (ICCD card no. 00-043-1051). Diffraction peaks of the $\mathrm{V}_{2} \mathrm{O}_{5}$ at $18.7^{\circ}, 37.6^{\circ}$, and $38.6^{\circ}$, which correspond to the (001), (401), and (311), planes, respectively, of the orthorhombic $\mathrm{V}_{2} \mathrm{O}_{5}$ (ICCD card no. 04-015-2250) are also observed. This result indicates a coexistence of the $\mathrm{V}_{2} \mathrm{O}_{5}$ and $\mathrm{VO}_{2}$ phases by the 1step calcination at $500^{\circ} \mathrm{C}$. To further investigate the effect of calcination condition, the pressure of the vacuum tube furnace was varied to $2 \times 10^{-3} \mathrm{mbar}$, while the temperature was maintained at $500^{\circ} \mathrm{C}$. As shown in Figure 1(b), XRD patterns of the orthorhombic $\mathrm{V}_{2} \mathrm{O}_{5}$ are dramatically reduced while those of the monoclinic $\mathrm{VO}_{2}$ are enhanced. In addition, diffraction peaks at $17.9^{\circ}, 25.7^{\circ}, 30.3^{\circ}, 32.6^{\circ}, 36.3^{\circ}$, $45.8^{\circ}, 50.1^{\circ}$, and $52.3^{\circ}$ corresponding to the (002), (110), (400), (-402), (-113), (005), (020), and (220) planes, respectively, of the $\mathrm{V}_{6} \mathrm{O}_{13}$ phase (ICCD card no. 04-008-4854) are present. This result indicates that lower vacuum pressure, the less amount of oxygen, promoted the formation of the $\mathrm{VO}_{2}$, as well as the $\mathrm{V}_{6} \mathrm{O}_{13}$ minor phase. This reduction condition at a temperature above $400^{\circ} \mathrm{C}$ and a pressure below $2 \mathrm{~Pa}\left(2 \times 10^{-2} \mathrm{mbar}\right)$ which caused the conversion of $\mathrm{V}_{2} \mathrm{O}_{5}$ thin films to $\mathrm{VO}_{2}$ has been reported by Ningyi et al. [22]. It was observed that the reduction process followed the sequence as $\mathrm{V}_{2} \mathrm{O}_{5} \longrightarrow \mathrm{V}_{3} \mathrm{O}_{7} \longrightarrow \mathrm{V}_{4} \mathrm{O}_{9} \longrightarrow \mathrm{V}_{6} \mathrm{O}_{13} \longrightarrow \mathrm{VO}_{2}$, namely, from $\mathrm{V}_{\mathrm{n}} \mathrm{O}_{2 \mathrm{n}+1}(n=2-4,6)$ to $\mathrm{VO}_{2}$. Therefore, lower pressure favoured $\mathrm{VO}_{2}$ formation caused by the oxygen deficiency $[22,23]$. To further investigate the effect of calcination time, the calcination soaking time was increased from 3 to $24 \mathrm{~h}$. It was found that the thin film consisted of only $\mathrm{V}_{2} \mathrm{O}_{3}$ phase.

Figure 1(c) shows XRD patterns of the thin films prepared by means of 1-step and 2-step calcination in the vacuum tube furnace at $500^{\circ} \mathrm{C}$ with the pressure of $2 \times 10^{-3}$ mbar. It is evident that only diffraction peaks of the monoclinic $\mathrm{VO}_{2}$ are present in the film prepared by 2-step calcination caused by the reduction process of $\mathrm{V}_{2} \mathrm{O}_{5}$ and $\mathrm{V}_{6} \mathrm{O}_{13}$.

SEM surface analysis of the $\mathrm{VO}_{2}$ thin film prepared by the 2-step calcination process at $500^{\circ} \mathrm{C}$ with the pressure of $2 \times 10^{-3}$ mbar (Figures $2(\mathrm{a})$ and $2(\mathrm{~b})$ ) reveals very fine $\mathrm{VO}_{2}$ grains with irregular shape of $\sim 220-380 \mathrm{~nm}$ in size surrounded by an amorphous phase of anhydrous vanadium oxide from gelation [24]. Film's thickness determined from a cross-sectional image (Figure 2(c)) is approximately 69-74 nm. Elemental composition analyzed by EDS (Figure 2(d)) reveals that the sample comprises of $\mathrm{Si}, \mathrm{O}, \mathrm{Na}$, $\mathrm{Ca}, \mathrm{V}, \mathrm{Mg}$, and $\mathrm{Al}$ at the amount of $30.1,51.0,8.5,5.7,1.5$,
2.6, and 0.6 At.\%, respectively. The $\mathrm{V}$ and $\mathrm{O}$ correspond to the $\mathrm{VO}_{2}$ thin film, and the others (and part of $\mathrm{O}$ ) correspond to the glass slide substrate. The elemental mappings of $\mathrm{Si}$ from the glass substrate and $\mathrm{V}$ from the $\mathrm{VO}_{2}$ film (Figures 2(e) and 2(f)) reveal homogeneous distribution of the $\mathrm{VO}_{2}$ grains in the thin film.

Typical surface XPS spectra of the $\mathrm{VO}_{2}$ sample are depicted in Figure 3. Detail-scan spectra were employed to investigate the valence electron of the $\mathrm{V}$ and $\mathrm{O}$ and to confirm phase purity of the thin films. According to the standard binding energy, a typical two-peak structure $(2 \mathrm{p} 3 / 2$ and $2 \mathrm{p} 1 / 2$ ) due to the spin-orbit splitting was observed [19]. The peaks at 516.1 and $523.8 \mathrm{eV}$ shown in Figure 3(a) correspond to binding energies for $\mathrm{V}_{2 \mathrm{p} 3 / 2}^{4+}$ and $\mathrm{V}_{2 \mathrm{p} 1 / 2}^{4+}$, respectively. The peaks at $517.6 \mathrm{eV}$ and $525.2 \mathrm{eV}$ correspond to $\mathrm{V}_{2 \mathrm{p} 3 / 2}^{5+}$ and $\mathrm{V}_{2 \mathrm{p} 1 / 2}^{5+}$, respectively. This result indicated atmospheric oxidation of a small amount of $\mathrm{V}^{5+}$ at the surface of the sample. The binding energy of $\mathrm{O}_{1 \mathrm{~s}}$ appears at 530.0, 531.8 , and $532.8 \mathrm{eV}$, which correspond to the $\mathrm{V}-\mathrm{O}$ bonding, $\mathrm{O}--\mathrm{H}$ bonding, and part of physically adsorbed $\mathrm{H}_{2} \mathrm{O}$, respectively, as shown in Figure 3(b). Besides these major energy levels, a number of less intense satellite peaks are also present. These $\mathrm{V}_{2 \mathrm{p}}$ satellite peaks are attributed to the $\mathrm{V}_{2} \mathrm{O}_{3}$. The XPS composition analysis result confirms the presence of $\mathrm{VO}_{2}$, as well as a small amount of $\mathrm{V}_{2} \mathrm{O}_{5}$ and $\mathrm{V}_{2} \mathrm{O}_{3}[25,26]$.

3.2. Electrical Properties of $\mathrm{VO}_{2}$ (M) Thin Films. Figure 4(a) illustrates the temperature dependence of electrical resistance of the $\mathrm{VO}_{2}$ thin films on the soda lime glass prepared by the 2 -step calcination process at $500^{\circ} \mathrm{C}$ with the pressure of $2 \times 10^{-3} \mathrm{mbar}$. The hysteresis loop indicates the metal-to-insulator transformation and the quality of the thin film. It was observed that surface resistance of the thin film decreased upon the heating process and increased upon the cooling process. The transition temperature, determined according to equation (1), was approximately $68^{\circ} \mathrm{C}\left(T_{c}=\left(80^{\circ} \mathrm{C}+56^{\circ} \mathrm{C}\right) / 2\right)$. Furthermore, resistivity profile of the $\mathrm{VO}_{2}$ thin films was nearly flat above the room temperature (semiconductor phase), indicating that the transition occurs at $68^{\circ} \mathrm{C}$ (metal-insulator transition phase) and constant at $80^{\circ} \mathrm{C}$ (metal phase), respectively [7, 27]. The $\mathrm{VO}_{2}$ thin films were transformed from monoclinic to tetragonal (rutile) phase at the transition temperature.

3.3. Optical Properties of $\mathrm{VO}_{2}(\mathrm{M})$ Thin Films. Figure 4(b) illustrates the optical transmittance spectra measured at 25 and $80^{\circ} \mathrm{C}$ of the $\mathrm{VO}_{2}$ thin films. Visible optical transmittance remains at $\sim 40-50 \%$ when the sample's temperature changes from 25 to $80^{\circ} \mathrm{C}$. However, for a near infrared (NIR) region wavelength range of $800-2500 \mathrm{~nm}$, the optical transmittance measured at $25^{\circ} \mathrm{C}$ is clearly 


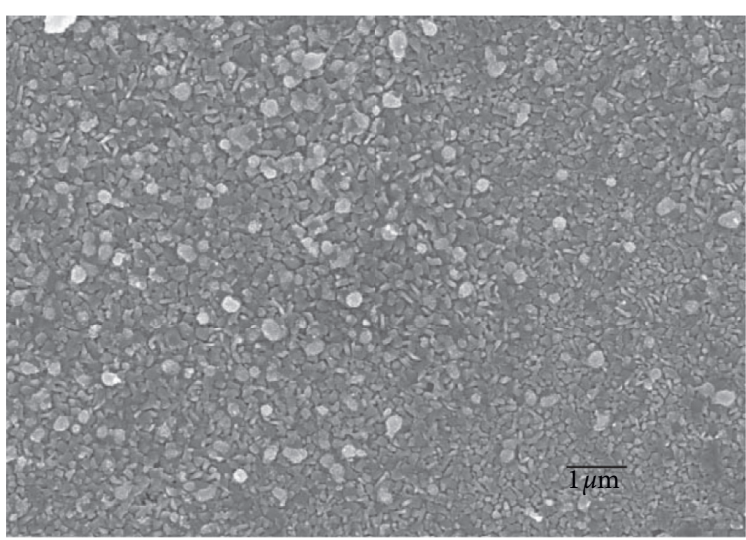

(a)

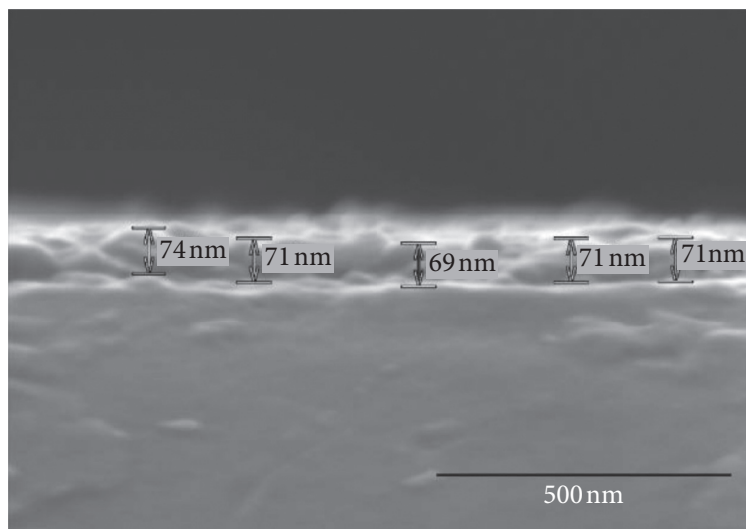

(c)

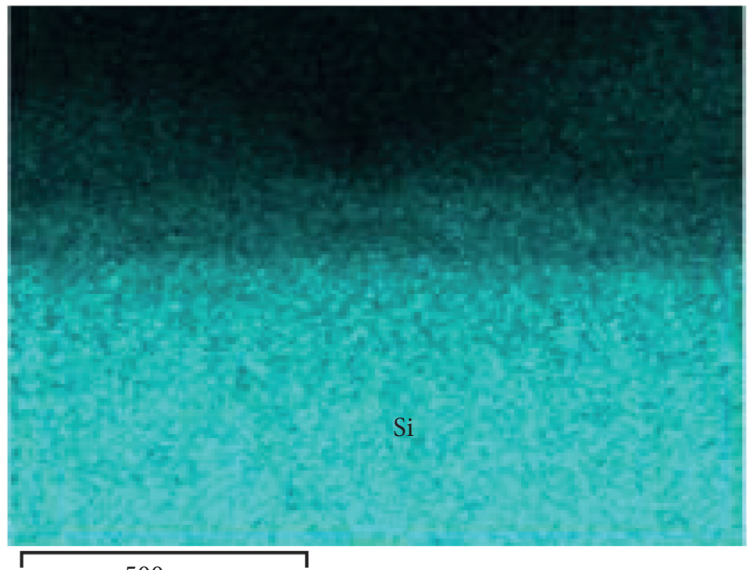

$500 \mathrm{~nm}$

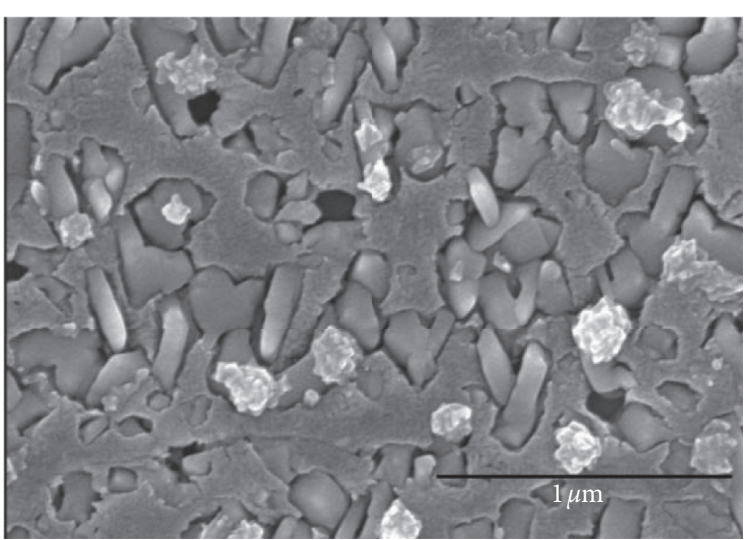

(b)

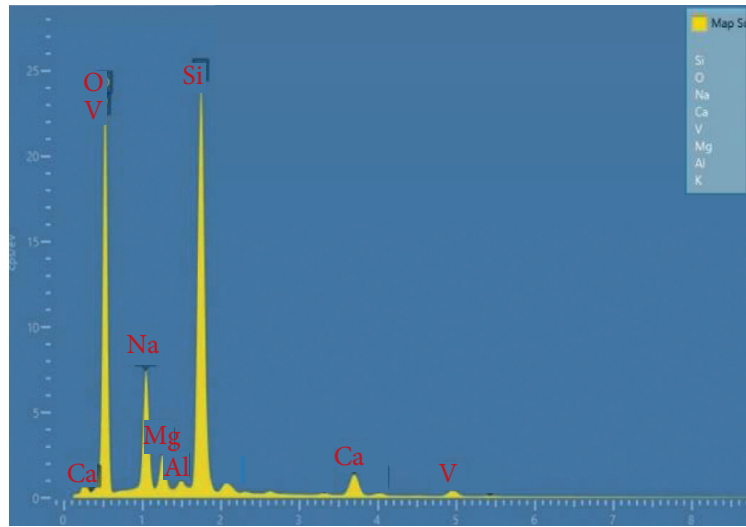

(d)

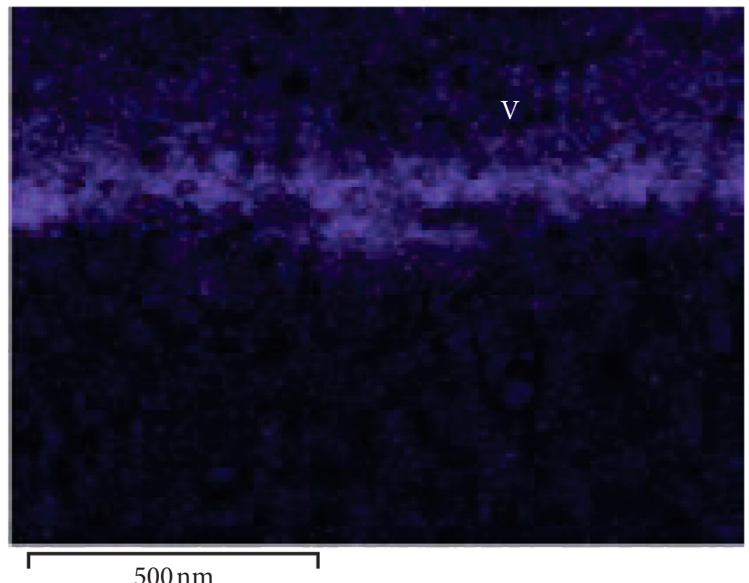

(f)

(e)

Figure 2: SEM images of the surfaceVO2 thin films at a resolution of x10,000 (a) and x50,000 (b) and cross-sectional image at x100,000 (c). Film's elemental composition analyzed by EDS (d), Si mapping (e), and V mapping (f).

higher than that measured at $80^{\circ} \mathrm{C}$. Moreover, the optical transmittance increases with increasing wavelength at $25^{\circ} \mathrm{C}$, while it reduces with increasing wavelength at $80^{\circ} \mathrm{C}$, indicating phase transition when the temperature is raised from 25 to $80^{\circ} \mathrm{C}$. Thus, the thin film exhibits thermochromic properties [28-30]. 


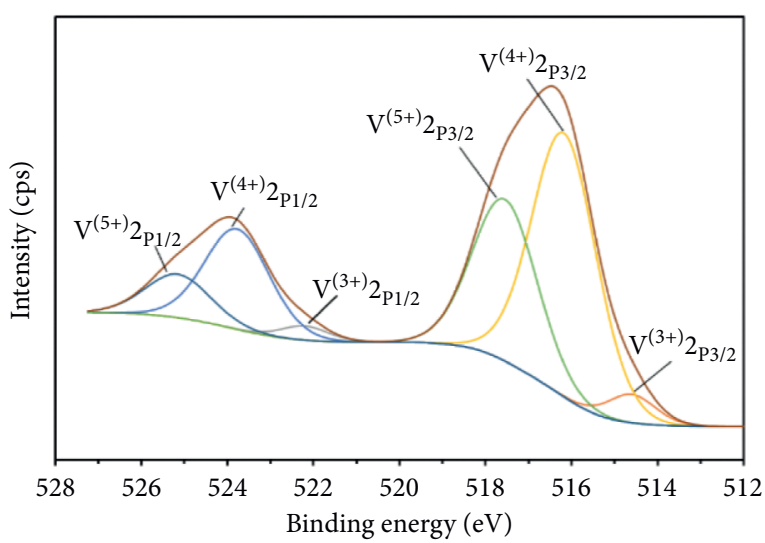

(a)

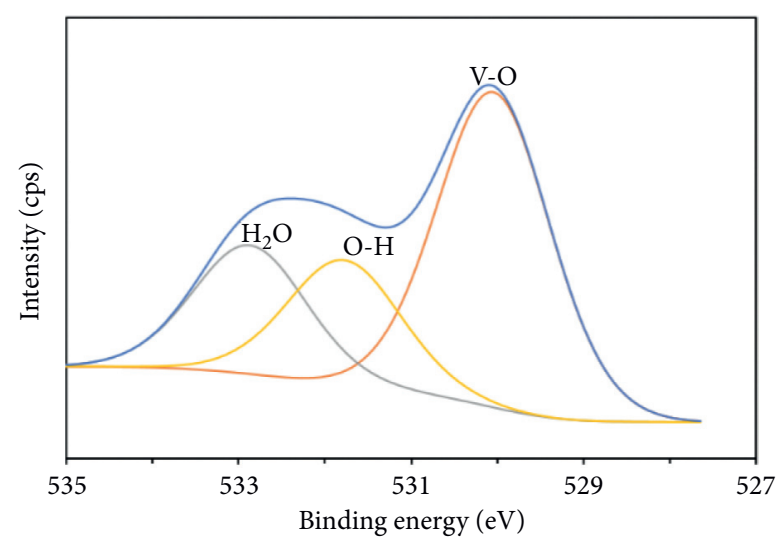

(b)

FIgURE 3: XPS spectra of the $\mathrm{VO}_{2}$ thin film; curve-fitted $\mathrm{V}_{2 \mathrm{p}}$ (a) and $\mathrm{O}_{1 \mathrm{~s}}$ (b) core level spectra.

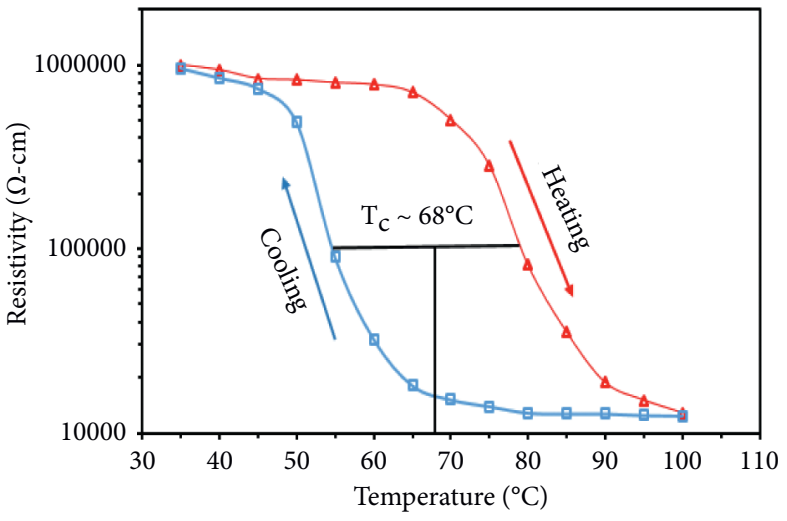

(a)

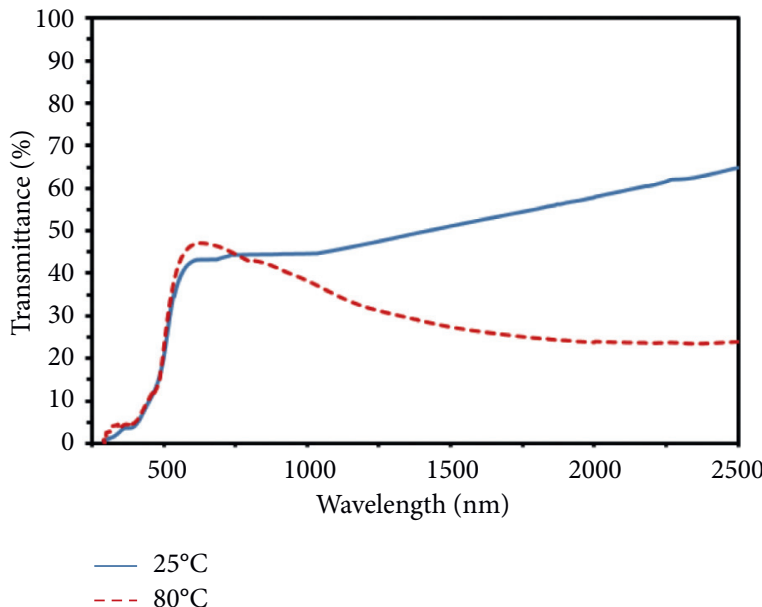

(b)

Figure 4: Thermal hysteresis loop (a) and the optical transmittance spectra (b) of $\mathrm{VO}_{2}$ thin films.

\section{Conclusions}

A simple and effective synthesis method for the preparation of the vanadium dioxide thin films on the glass slide substrate has been demonstrated by a sol-gel dip coating at low temperature of $500^{\circ} \mathrm{C}$ in a vacuum tube furnace at a pressure of $2 \times 10^{-3} \mathrm{mbar}$. The calcination was performed by 2 steps, in which thin films were heated in a tube furnace to $500^{\circ} \mathrm{C}$ at a heating rate of $2^{\circ} \mathrm{C} / \mathrm{min}$, soaked for $3 \mathrm{~h}$, and cooled down to room temperature, and the same process was repeated. The analyses revealed that the thin films consisted of monoclinic $\mathrm{VO}_{2}$ phase and a small amount of $\mathrm{V}_{2} \mathrm{O}_{5}$ and $\mathrm{V}_{2} \mathrm{O}_{3}$ phases. The very fine $\mathrm{VO}_{2}$ grains with irregular shape of $\sim 220-380 \mathrm{~nm}$ in size were homogeneously distributed on the surface. The film's thickness was in a range of 69-74 nm. The monoclinic to tetragonal (rutile) phase transition temperature was $68^{\circ} \mathrm{C}$. The thin films exhibited good thermochromic properties. The low-temperature synthesis would be beneficial for thermochromic thin film coating on a conventional soda lime glass panel. In addition, as no intermediate gas was employed during calcination, the process would be suitable for large-scale fabrication.

\section{Data Availability}

The data used to support the finding of this study are included within the article.

\section{Conflicts of Interest}

The authors declare that there are no conflicts of interest regarding the publication of this paper.

\section{Acknowledgments}

This study was financially supported by the Thailand Graduate Institute of Science and Technology (TGIST, no. SCA-CO-2559-2296-TH) in National Science and 
Technology Development Agency (NSTDA), Center of Excellence in Nanotechnology for Energy (CENE), Center of Excellence in Metal and Materials Engineering (CEMME), Graduate School of Engineering, Prince of Songkla University. The authors extend their thanks to the Department of Mining and Materials Engineering, Faculty of Engineering, Prince of Songkla University.

\section{References}

[1] M. M. Seyfouri and R. Binions, "Sol-gel approaches to thermochromic vanadium dioxide coating for smart glazing application," Solar Energy Materials and Solar Cells, vol. 159, pp. 52-65, 2017.

[2] P. Ashok, Y. S. Chauhan, and A. Verma, "Vanadium dioxide thin films synthesized using low thermal budget atmospheric oxidation," Thin Solid Films, vol. 706, Article ID 138003, 2020.

[3] S.-E. Chen, H.-H. Lu, S. Brahma, and J.-L. Huang, "Effects of annealing on thermochromic properties of $\mathrm{W}$-doped vanadium dioxide thin films deposited by electron beam evaporation," Thin Solid Films, vol. 644, pp. 52-56, 2017.

[4] W. Li, S. Ji, K. Qian, and P. Jin, "Preparation and characterization of $\mathrm{VO} 2(\mathrm{M})-\mathrm{SnO} 2$ thermochromic films for application as energy-saving smart coatings," Journal of Colloid and Interface Science, vol. 456, pp. 166-173, 2015.

[5] S. Taylor, L. Long, and L. Wang, "Fabrication and characterization of furnace oxidized vanadium dioxide thin films," Thin Solid Films, vol. 682, pp. 29-36, 2019.

[6] M. Kong, K. Egbo, Ch. P. Liu et al., "Rapid thermal annealing assisted facile solution method for tungsten-doped vanadium dioxide thin films on glass substrate," Journal of Alloys and Compounds, vol. 833, Article ID 155053, 2020.

[7] D. Li, Y. Shan, F. Huang, and S. Ding, "Sol-gel preparation and characterization of $\mathrm{SiO} 2$ coated $\mathrm{VO} 2$ films with enhanced transmittance and high thermochromic performance," Applied Surface Science, vol. 317, pp. 160-166, 2014.

[8] J. Wu, W. Huang, Q. Shi et al., "Effect of annealing temperature on thermochromic properties of vanadium dioxide thin films deposited by organic sol-gel method," Applied Surface Science, vol. 268, pp. 556-560, 2013.

[9] Q. Song, H. Pang, W. Gong et al., "Enhancing phase-transition sensitivity of tungsten-doped vanadium dioxide by high-temperature annealing," Materials Letters, vol. 161, pp. 244-247, 2015.

[10] A. Pergament, G. Stefanovich, O. Berezina, and D. Kirienko, "Electrical conductivity of tungsten doped vanadium dioxide obtained by the sol-gel technique," Thin Solid Films, vol. 531, pp. 572-576, 2013.

[11] O. Berezina, D. Kirienko, A. Pergament, G. Stefanovich, A. Velichko, and V. Zlomanov, "Vanadium oxide thin films and fibers obtained by acetylacetonate sol-gel method," Thin Solid Films, vol. 574, pp. 15-19, 2015.

[12] N. Wang, S. Magdassi, D. Mandler, and Y. Long, "Simple solgel process and one-step annealing of vanadium dioxide thin films: synthesis and thermochromic properties," Thin Solid Films, vol. 534, pp. 594-598, 2013.

[13] A. Velichko, A. Pergament, V. Putrolaynen, O. Berezina, and G. Stefanovich, "Effect of memory electrical switching in metal/vanadium oxide/silicon structures with VO2 films obtained by the sol-gel method," Materials Science in Semiconductor Processing, vol. 29, pp. 315-320, 2015.

[14] S.-D. Lan, C.-C. Cheng, C.-H. Huang, and J.-K. Chen, "Synthesis of sub-10 nm VO2 nanoparticles films with plasma-treated glass slides by aqueous sol-gel method," Applied Surface Science, vol. 357, pp. 2069-2076, 2015.

[15] L. Chotirat, S. Niyomwas, S. Supothina, W. Wongpisan, and $\mathrm{K}$. Waree, "Synthesis and electrical resistance property of vanadium oxide thin films by DC magnetron sputtering," Materials Science Forum, vol. 998, pp. 185-190, 2020.

[16] P. Phoempoon and L. Sikong, "Phase transformation of $\mathrm{VO}_{2}$ nanoparticles assisted by microwave heating," The Scientific World Journal, vol. 2014, Article ID 841418, 8 pages, 2014.

[17] S. E. Zaki, M. A. Basyooni, M. Shaban et al., "Role of oxygen vacancies in vanadium oxide and oxygen functional groups in graphene oxide for room temperature $\mathrm{CO} 2$ gas sensors," Sensors and Actuators A: Physical, vol. 294, pp. 17-24, 2019.

[18] T. Ivanova, A. Harizanova, M. Surtchev, and Z. Nenova, "Investigation of sol-gel derived thin films of titanium dioxide doped with vanadium oxide," Solar Energy Materials and Solar Cells, vol. 76, no. 4, pp. 591-598, 2003.

[19] Z. Liang, L. Zhao, W. Meng et al., “Tungsten-doped vanadium dioxide thin films as smart windows with self-cleaning and energy-saving functions," Journal of Alloys and Compounds, vol. 694, pp. 124-131, 2017.

[20] P. Deepak Raj, S. Gupta, and M. Sridharan, "Nanostructured V2O5 thin films deposited at low sputtering power," Materials Science in Semiconductor Processing, vol. 39, pp. 426-432, 2015.

[21] Y. Li, P. Jiang, W. Xiang, F. Ran, and W. Cao, "A novel inorganic precipitation-peptization method for VO 2 sol and VO 2 nanoparticles preparation: synthesis, characterization and mechanism," Journal of Colloid and Interface Science, vol. 462, pp. 42-47, 2016.

[22] Y. Ningyi, L. Jinhua, and L. Chenglu, "Valence reduction process from sol-gel V2O5 to VO2 thin films," Applied Surface Science, vol. 191, no. 1-4, pp. 176-180, 2002.

[23] K. Shibuya and A. Sawa, "Optimization of conditions for growth of vanadium dioxide thin films on silicon by pulsedlaser deposition," AIP Advances, vol. 5, Article ID 107118, 2015.

[24] Y. Liu, J. Liu, Y. Li et al., "Effect of annealing temperature on the structure and properties of vanadium oxide films," Optical Materials Express, vol. 6, no. 5, Article ID 259637, 2016.

[25] K. Li, M. Li, C. Xu et al., " $\mathrm{VO}_{2}(\mathrm{M})$ nanoparticles with controllable phase transition and high nanothermochromic performance," Journal of Alloys and Compounds, vol. 816, Article ID 152655, 2020.

[26] D. Mukherjee, A. Dey, A. C. M. Esther et al., "Reversible, repeatable and low phase transition behaviour of spin coated nanostructured vanadium oxide thin films with superior mechanical properties," Ceramics International, vol. 44, no. 8 , pp. 8913-8921, 2018.

[27] Z. Huang, S. Chen, B. Wang et al., "Vanadium dioxide thin film with low phase transition temperature deposited on borosilicate glass substrate," Thin Solid Films, vol. 519, no. 13, pp. 4246-4248, 2011.

[28] R. Li, S. Ji, Y. Li, Y. Gao, H. Luo, and P. Jin, "Synthesis and characterization of plate-like VO2(M)@SiO2 nanoparticles and their application to smart window," Materials Letters, vol. 110, pp. 241-244, 2013.

[29] C. Liu, S. Wang, Y. Zhou et al., "Index-tunable anti-reflection coatings: maximizing solar modulation ability for vanadium dioxide-based smart thermochromic glazing," Journal of Alloys and Compounds, vol. 731, pp. 1197-1207, 2018.

[30] Z. Qu, L. Yao, Y. Zhang, B. Jin, J. He, and J. Mi, "Surface and interface engineering for $\mathrm{VO} 2$ coatings with excellent optical performance: from theory to practice," Materials Research Bulletin, vol. 109, pp. 195-212, 2019. 